\title{
OPINIÓN
}

\section{El regionalismo a examen. La crisis global de la integración}

Lección inaugural Universidad Loyola Andalucía, 2018/2019

\section{Pedro Caldentey del Pozo'}

Querido Padre Provincial, Rector Magnífico, Presidente de la Fundación Universidad Loyola Andalucía, Sres. Vicerrectores, invitados y autoridades de la sala, queridos colegas de Loyola Andalucía, estimadas amigas, estimados amigos,

Este siglo ha empezado con un ritmo frenético. Como las primeras décadas del siglo XX, las de este siglo XXI están resultando desbordantes tanto por la intensidad de los cambios que percibimos en todos los ámbitos de nuestra vida, como por las pistas que tenemos sobre cómo será el siglo XXI para nuestros estudiantes o nuestros hijos. Es ahora difícil adivinar cómo resumiremos los locos años veinte del $\mathrm{XXI}$ o cuáles serán las vanguardias que celebraremos. $\mathrm{O}$ si lo que celebraremos serán los cambios en las relaciones sociales y los nuevos modelos de familia, o la transformación de las ciudades o los coches sin conductor. O la extensión de una vida sin enfermedades o vejez.

Hay voces instaladas en el optimismo y que invocando a Steven Pinker ly su libro de 2018 En defensa de la llustración) y otros autores reclaman que nunca tanta gente vivió mejor que ahora. Pero los inicios del siglo XXI comparten con los comienzos del siglo XX las tensiones e incertidumbres que llenaron esa época de ira y de destrucción. Algunos líderes perturbadores y la proliferación de "ismos" no nos permiten olvidar los riesgos que nos rodean.

' Director, Departamento de Economía. Universidad Loyola Andalucía. 
Estamos en medio de un cambio de época que nos empuja a dibujar un escenario de crisis que, con suerte, será sólo una transición. Una de las múltiples dimensiones de este escenario de crisis es la que afecta a la gobernabilidad de un mundo donde tiemblan los equilibrios que lo regían.

Imaginen ahora que estamos en 1994. Nos gobiernan Mandela, Helmut Kohl, Mitterrand y Felipe González. Y también Clinton, Yeltsin, Fernando Henrique Cardoso, Ernesto Zedillo, Suharto, Boutros-Ghali, Jacques Santer o Juan Pablo II. Termina finalmente la Ronda Uruguay del GATT y va a nacer la Organización Mundial de Comercio. Estados Unidos y Clinton han lanzado a los países latinoamericanos la idea que propuso Bush padre sobre la creación del Área de Libre comercio de las Américas. Ha entrado en vigor el NAFTA (Tratado de libre comercio de América del Norte) con el susto inicial de la rebelión zapatista. La UE ha conseguido, tras

\section{FIGURA I. EI "Spaguetti Bowl” de los acuerdos comerciales de Jagdish Bhagwati}

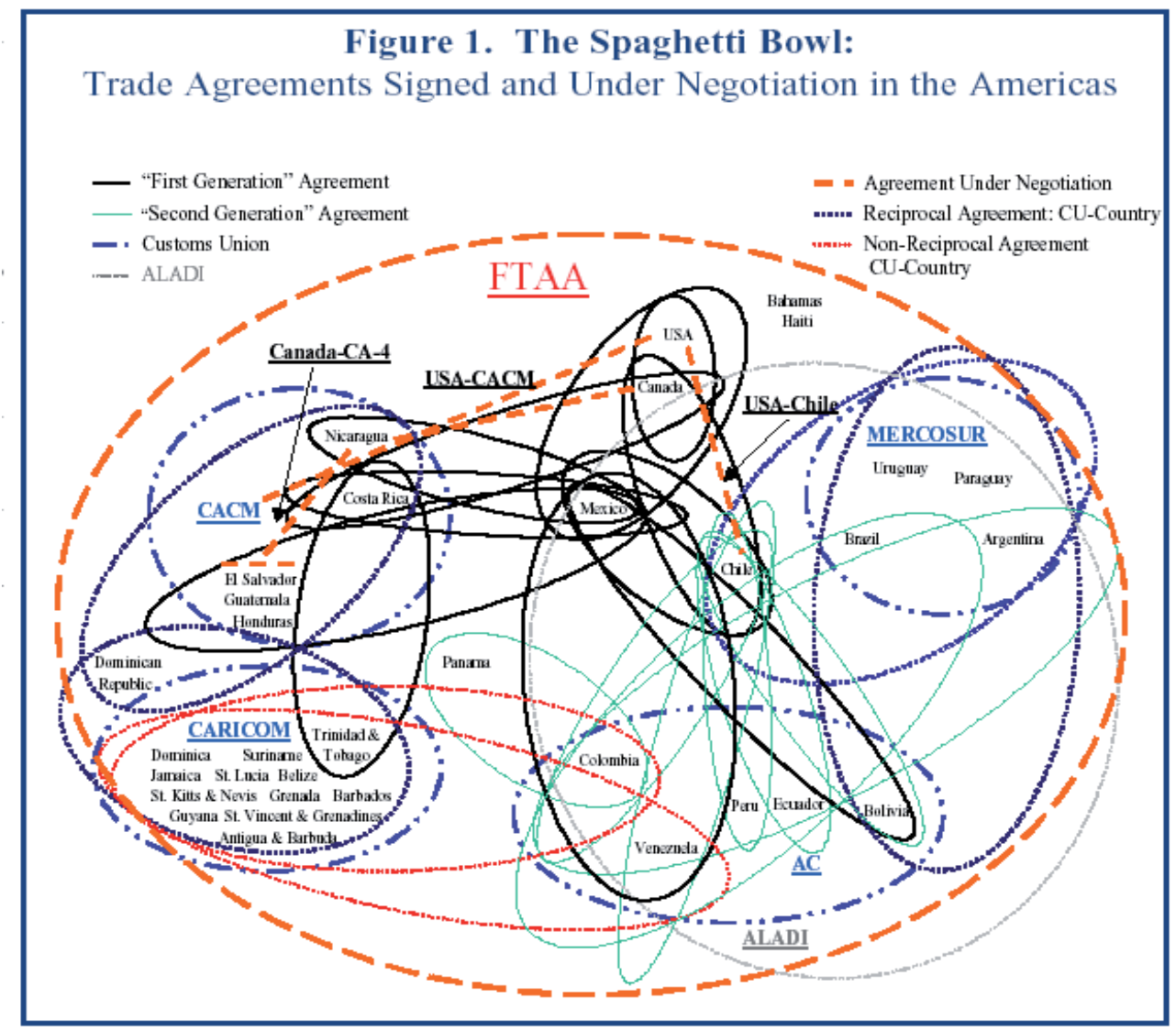

Fuente: IDB. 
algún sobresalto en forma de referéndum, que entré en vigor el Tratado de Maastricht que da paso a la Unión Monetaria Europea. En 1994 se ha creado el Instituto Monetario Europeo, antecedente del BCE. Proliferan los acuerdos comerciales en todo el mundo. Nadie se imagina a China como un competidor gigante sino como un suculento mercado En 1994 China hace su primera conexión a Internet.

La última década del siglo pasado y la primera de éste se caracterizaron por la expansión del multilateralismo y de la globalización. Los acuerdos regionales de libre comercio o integración crecían alrededor de la Organización Mundial de Comercio como aceleradores del multilateralismo o potenciadores de las posiciones de algunos bloques en la globalización. El resultado de esa expansión dio lugar a lo que el prof. Jadish Bhagwati de Columbia University denominó el Spaguetti Bowl, donde cada línea es un acuerdo y que reflejaba el enorme lío de acuerdos de todo tipo en los que estaba involucrada América Latina.

\section{FIGURA 2. Regionalismo Global. El "Spaguetti Bowl” de los acuerdos comerciales en 2014}

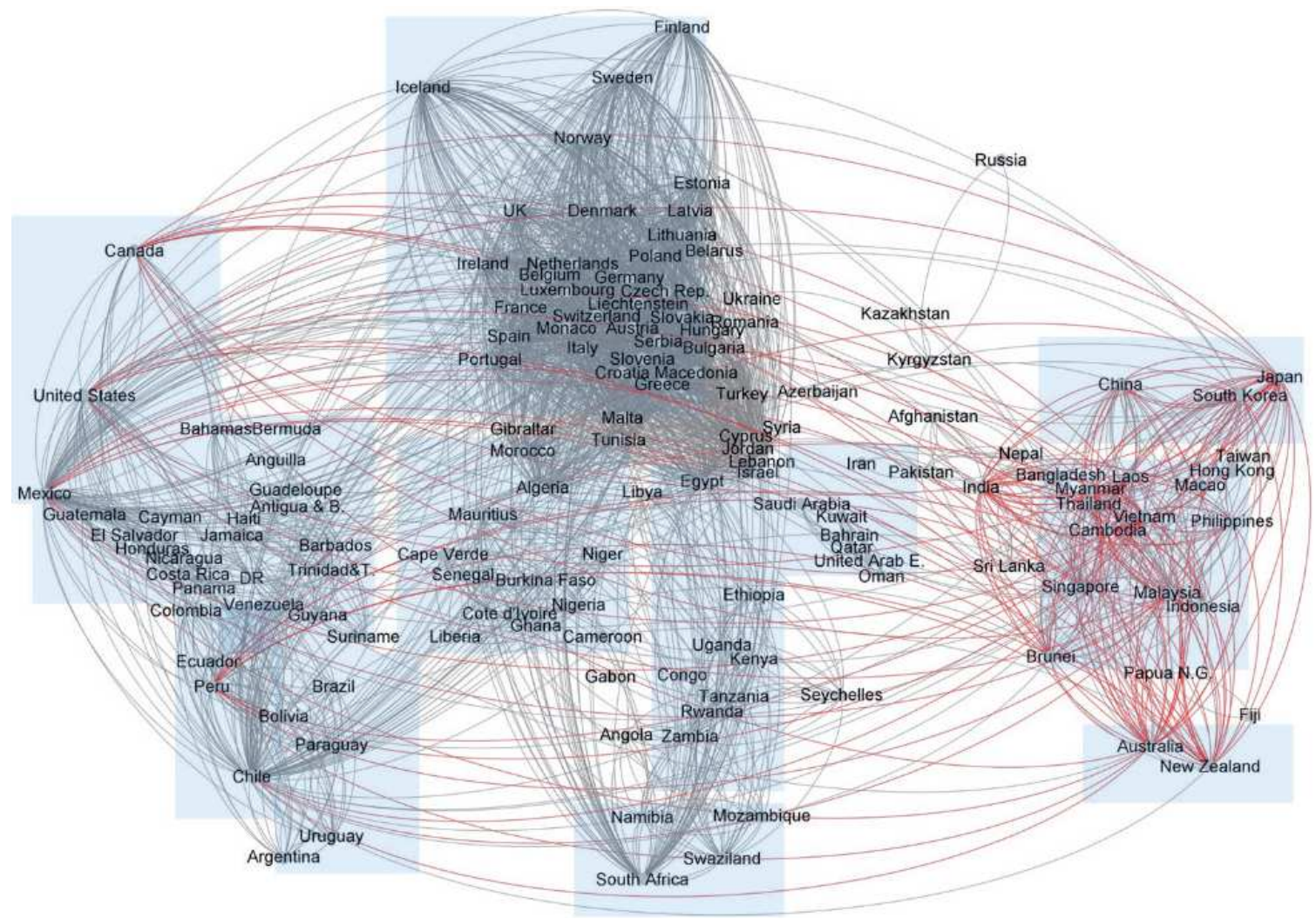

Fuente: IDB Integration and Trade Sector based on INTrade. 
En enero de 2014 organizamos desde la Universidad Loyola Andalucía y su Instituto de investigación en desarrollo, la Fundación ETEA, un seminario sobre la integración regional en América Latina con la SEGIB, el SICA y el MAEC-AECID a la que asistieron representantes de organismos multilaterales y de acuerdos latinoamericanos de integración junto a académicos de varios países que convocamos para el debate. Antoni Estevadeordal, entonces gerente del Sector de integración y comercio del BID revisó el mapa de los acuerdos regionales mostrando la explosiva secuencia de acuerdos regionales de los últimos 50 años. Desde la consolidación de la integración regional en Europa en los años 50 y 60, a su prolongación en América Latina en los años 60 y 70, a la que se suma Oriente Medio en los años 80 , que se extiende por todo el mundo en los años 90 y se multiplica al inicio de siglo hasta completar la tupida telaraña actual de acuerdos.

Cómo será el gráfico de 2025 es una pregunta verdaderamente intrigante. El Spaguetti Bowl de los noventa o esta telaraña más reciente han sido valorados en general con una sensación de dinámico optimismo que supera el desorden que sugiere la imagen. El concepto anglosajón de regionalismo, también conocido como "regionalismo abierto", le ofrece sentido y coherencia al lío de acuerdos, acudiendo a su visión laxa y dúctil de la naturaleza de los acuerdos y porque los ha entendido como promotores de la apertura y la liberalización.

El regionalismo abierto mezcla acuerdos de naturaleza muy diferente. Insistimos desde esta universidad en que para analizar el regionalismo es preciso diferenciar la naturaleza diversa de los Acuerdos de libre comercio, de los Procesos de integración regional o de los Acuerdos de cooperación, colaboración o complementariedad.

La visión anglosajona del regionalismo tenía en los 90 una mirada escéptica sobre la UE que todavía mantiene. En la academia o la diplomacia anglosajona, la Unión Europea es percibida como una excepcionalidad ciertamente sospechosa en el mapa del regionalismo global.

Sospechosa para Europa, pero nociva para América Latina, donde la integración latinoamericana conduce presunta pero irremediablemente a la retórica, la ineficiencia, y la obsolescencia competitiva. Así describían Maurice Schiff y Alan Winters desde el Banco Mundial los acuerdos de integración en un libro donde por fin se contemplaban los procesos clásicos de integración en el análisis del regionalismo, aunque fuera para cuestionarlos:

La propagación del regionalismo no evidencia en forma alguna sus virtudes. En un mundo regionalizado un país se puede hallar en mejor situación estando dentro de un ARI que fuera de éste, aunque esto no indica con seguridad que dicho país prefiera un mundo regionalizado a uno no regionalizado. Para ofrecer una ilustración gráfica, si se suscita 
una riña de pandillas en el vecindario, posiblemente convenga más ser parte de una pandilla, pero esto no hace que las pandillas sean algo recomendable. ${ }^{2}$

Pero la época dorada del multilateralismo y el regionalismo acelerados del libre comercio cambió de forma drástica en la segunda década del siglo XXI, o para ser más preciso, desde los previos de la Gran Recesión. El atasco no resuelto de lo multilateral y especialmente de la OMC ha sido un factor principal del cambio de escenario. Las razones del atasco han sido diversas, pero podemos destacar dos entre todas ellas:

A. La aparición de las economías emergentes y su aprovechamiento de los beneficios de la globalización (China especialmente).

B. Y La estupefacción de las economías occidentales avanzadas (EU, USA, Japón) al percibir que la ganancia neta obtenida por la globalización era mucho menor de lo esperado y dejaba además una larga lista de perdedores dentro de sus fronteras.

Quizás ha sido Dani Rodrik, una referencia fundamental en el análisis del comercio internacional y su impacto en el desarrollo, quien ha explicado mejor la naturaleza de la crisis con su -ya clásico- gráfico sobre el trilema de la globalización.

\section{FIGURA 3. El trilema de la hiperglobalización de Dani Rodrik}

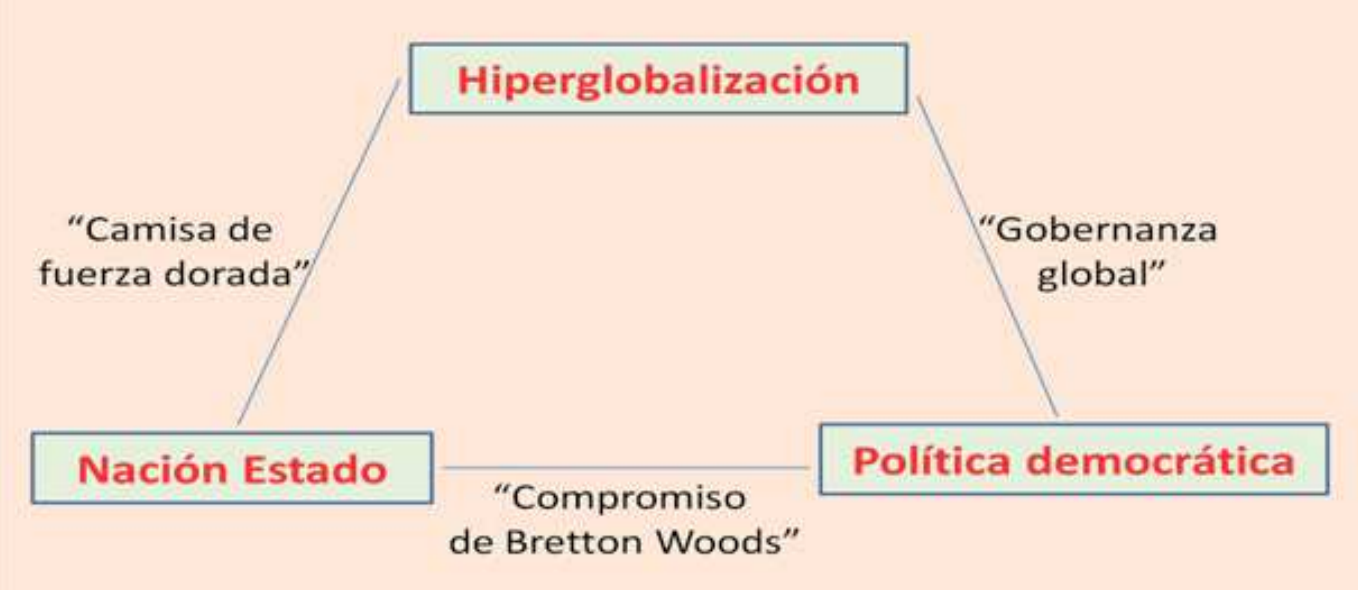

Fuente: Elaboración propia.

2 SCHIFF, M. y WiNTERS, A. (2003) Integración regional y desarrollo, Colombia (edición en español), Alfaomega y Banco Mundial, p. 249. 
Si recuerdan, la tesis de Rodrik, en su libro La paradoja de la Globalización del año 2012, es que hay tres fuerzas que explican el comportamiento de la sociedad globalizada pero que la profundización simultánea de las tres es incompatible. Por lo que nos vemos obligados a escoger entre dos de ellas. Aparecen entonces tres escenarios. Uno deseable pero que parece imposible, que es el de un federalismo global inclusivo y democrático donde los consensos de desarrollo protegen el interés común frente al predominio de los intereses nacionales y particulares. Otro escenario que es el que hoy nos asusta más, el de la camisa de fuerza dorada, donde cada país juega sus bazas, como hacíamos en el siglo XIX en el marco del patrón oro, con la democracia como la dimensión sacrificada. Y un tercero, más probable, en el que, limitando la profundidad de la globalización, acordemos unas reglas globales de gobierno al estilo de lo que hicimos en Bretton Woods.

\section{Pero avancemos hacia el objeto principal de esta lección inaugural. Si esta crisis lo es del multilateralismo y la globalización, ¿por qué hablamos entonces de la crisis del regionalismo?}

Hay en la agenda global varios elementos que dan forma y sentido a esta expresión de la crisis del regionalismo.

1. Primero, la crisis de los mega acuerdos de libre comercio.

2. Segundo, el neoproteccionismo de algunos países $y$, en especial de EEUU, tradicional guardián del multilateralismo.

3. Tercero, la crisis del regionalismo latinoamericano.

4. Y, en cuarto lugar, la crisis de la UE.

Los mega-acuerdos regionales no forman parte de los años dorados de la globalización. Son reacciones a la crisis del multilateralismo, intentos de las viejas potencias occidentales por capturar mejor los beneficios de la globalización (en el caso del TTIP - Transatlantic Trade and Investment Partnership entre EEUU y la UE) o para compartir o competir mejor con los ganadores asiáticos de la globalización (TransPacific Partnership-TPP). Incluso el único sobreviviente de todos ellos, el CETA (Comprehensive Economic and Trade Agreement entre Canadá y la UE), forma parte de esa lógica. El regionalismo ya no es un acelerador de la globalización sino una herramienta para competir, para defender mercados.

La agenda del libre comercio ha cambiado mucho con respecto a los acuerdos de los noventa. Hoy el acceso a mercados no es el asunto principal en los acuerdos 
de libre comercio dado el bajo nivel global de protección arancelaria. Son más relevantes las negociaciones sobre las medidas no arancelarias relacionadas con barreras técnicas, sanitarias y fitosanitarias, legales o fiscales.

Los nuevos acuerdos incorporan también sensibles negociaciones sobre el intercambio de servicios, propiedad intelectual, protección de las inversiones, impactos medioambientales, acceso a compras públicas, la regulación de subsidios desde el estado o la protección de los derechos laborales.

Se trata de una agenda amplia, de gran impacto, que explica el debate sobre las negociaciones. Entre todas ellas, son las normas sobre arbitrajes de diferencias y conflictos entre el Estado y el inversor extranjero las que se han convertido en un tema central de controversia porque pueden forzar la imposición de regulaciones que limiten las reglas, decisiones o enfoques nacionales del desarrollo.

Los movimientos de rechazo a estos acuerdos desde algunos sectores políticos han sido muy significativos en la UE durante las negociaciones del Transatlantic Trade and Investment Partnership (TIP) y en EEUU por el TPP. Y concuerdo con que estas críticas son una frontera necesaria y razonable para definir los límites de la hiperglobalización, como también lo son las medidas sobre la fiscalidad internacional, las leyes antimonopolio o el abuso de posición dominante de mercado de las multinacionales. Un asunto sobre el que sí llegan buenas sensaciones desde la Unión Europea.

Uno de los últimos episodios del neoproteccionismo de EEUU ha sido el caso de la renegociación del NAFTA. Un episodio que se resolvió con un notable ejercicio de pirotecnia negociadora, con más ruido que nueces, aunque con una menor y significativa alteración de las bases del acuerdo original en favor de Estados Unidos ${ }^{3}$.

Eso sí, los efectos a largo plazo de estos ajustes no son evidentes. Una de las referencias principales para estudiar desde Estados Unidos los efectos de las políticas comerciales es el Peterson Institute for International Economics, un think tank ubicado en Washington.

\footnotetext{
${ }^{3}$ Después de la redacción de este discurso, y cerrada la renegociación del NAFTA, se han producido nuevos episodios de amenaza de guerra comercial, siempre impulsado por el gobierno de Donald Trump. Tienen especial trascendencia las amenazas de escalada proteccionista hacia la Unión Europea y China. El patrón se ha repetido y la amenaza de gran escala tiene a retirarse provocando ciertas renegociaciones específicas. El coste de la incertidumbre que estos episodios generan es una variable determinante en la evolución reciente de la economía mundial.
} 
Sobre la reciente negociación del NAFTA decía uno de sus expertos algo que da una idea de lo difícil que es ser proteccionista hoy en una economía globalizada. El análisis del Peterson Institute terminaba haciendo esta pregunta:

Entonces, ¿es la estrategia de Trump con México un éxito? Algunos fabricantes de automóviles y trabajadores de EE. UU. podrán beneficiarse de las costosas y nuevas reglas de origen de Trump, respaldadas por su amenaza de imponer restricciones comerciales a los automóviles que vienen de fuera de Norte América (léase EEUU). Podría haber más contenido local y una presión competitiva menos directa de las importaciones de Japón, Corea del Sur o Europa.

Pero estas "ganancias" están más que compensadas por las desventajas económicas. El aumento de los costes implica precios más altos para los consumidores estadounidenses. Igualmente importante es el deterioro de la competitividad de Norte América como plataforma de exportación global para los fabricantes de automóviles. A medida que se desacelera el crecimiento del consumidor en América del Norte, las compañías evaluarán dónde pueden producir de manera más competitiva para acceder a mercados emergentes en Asia, América del Sur y en otros lugares. Las nuevas reglas y costos más altos hacen de América, México y Canadá un centro considerablemente menos atractivo.

El éxito de Trump al intimidar a otro país para que acepte un trato comercial mutuamente malo no es un logro económico. Los políticos extranjeros pueden apaciguar a la Casa Blanca para evitar un resultado peor. Pero eso no debe confundirse con una buena política. ${ }^{4}$

No obstante, quizás no conviene, si me permiten la sugerencia, y pese el discurso simplón que lo promueve (el de America First) anatemizar el rechazo a los acuerdos exclusivamente como un asunto de un nacionalismo ciego o del autoritarismo o el populismo. Y no conviene hacerlo porque

A. Primero, porque los acuerdos comerciales no han ofrecido evidencias imbatibles de su infinita bondad. Algunos acuerdos sirven, otros no; algunos acuerdos sirven a unos, y perjudican a otros.

B. Segundo, porque sus efectos internos negativos se han hecho más visibles al extenderse en nuestros países y corregir los excesos de la competitividad basada en la eficiencia no es una posición absurda.

C. Tercero, porque su lógica es poco compatible con el desarrollo de políticas industriales y la promoción de nuevas pautas de desarrollo que hoy han entrado en la agenda de debate teórico de la economía del desarrollo de la mano de Dani Rodrik desde Harvard; o Ha Joon Chang desde Cambridge o Justin Yifu

\footnotetext{
${ }^{4}$ Peterson Institute, "Sweating the Auto Details of Trump's Trade Deal with Mexico", Chad P. Bown (PIIE) https://piie.com/blogs/trade-investment-policy-watch/sweating-auto-details-trumps-trade-deal-mexico.
} 
Lin (anterior Chief Economist del Banco Mundial y actual Decano del Institute for New Structural Economics).

Creo que ha pasado el momento estelar de los acuerdos de libre comercio. Evitar un rebrote dañino del neoproteccionismo sería un error que hay que evitar activamente. Pero quizás es el momento de que los TLC pasen a la retaguardia de los instrumentos de política económica tras 30 años de protagonismo estelar.

Quiero ya hacer especial énfasis en dos ámbitos de la integración regional que hemos estudiado a fondo en esta universidad: el caso europeo y el caso latinoamericano. Pero déjenme antes hacer algunas consideraciones metodológicas sobre el estudio del regionalismo.

El primero es que, como habrán apreciado, y es especialmente determinante en estos momentos, el enfoque de análisis del regionalismo y la integración regional es necesariamente multidisciplinar. La economía por si sola es ciertamente útil hablando de aspectos concretos de la integración económica. Por ejemplo, con mis colegas del departamento (Adolfo Cristóbal, Alejandro Cardenete y Olexandr Nekhay) acabamos de publicar un análisis del impacto que tendría para las economías centroamericanas el escenario de apostar por el desarrollo completo de la Unión Aduanera en la región frente al escenario de acelerar la desgravación arancelaria y otros elementos del CAFTA con Estados Unidos. El resultado es que, ahora mismo, las ganancias de la primera opción son mejores en términos globales para los centroamericanos. Créanme que pese a la lógica y las evidencias, este resultado no es suficiente para el necesario cambio de énfasis en la política económica de la región que sugieren los datos. Las relaciones internacionales, las decisiones institucionales, y las posiciones de los actores relevantes están condicionadas por factores muy diversos que van desde la calidad de las instituciones, hasta el compromiso - débil- de las élites el bien común.

Los principales debates en torno al regionalismo no se pueden abordar, por tanto, sin un enfoque multidisciplinar. En el caso de la integración económica en Latinoamérica o Europa, hay que recurrir al menos a enfoques de economía política. Por ejemplo para comprender la coalición de intereses que hay detrás de la negociación de un acuerdo de libre comercio, o para descifrar los problemas de la Unión Monetaria Europea.

Mi trayectoria como investigador es también un efecto de ello. Cuando decidí con José Juan Romero, mi maestro y director de tesis, escoger la unión aduanera 
centroamericana como tema de tesis doctoral, acabamos estudiando la institucionalidad regional y sus dinámicas para explicar por qué no se había movido nada tras un consenso abrumador en torno a sus ventajas.

La necesidad de acudir a las relaciones internacionales, a la economía o al estudio de las normas e instituciones hace rico pero complejo el estudio de la integración regional debido al conocimiento fragmentado que deriva de la frecuente falta de comunicación entre las diferentes perspectivas teóricas o de la falta de interacción entre académicos de diferentes disciplinas.

Hay más temas metodológicos importantes relacionados con el problema de comparar en la integración regional comparada. En general, la diversidad de enfoques y disciplinas genera un amplio rango de definiciones (regionalismo, integración, libre comercio o acudiendo al inglés regionalism, regioness, regionhood) y hay pocos consensos en torno a ellos. Además, el objeto de estudio es heterogéneo. La naturaleza diversa de los regionalismos o el tamaño geográfico de las iniciativas o sus peculiaridades culturales hacen difícil universalizar el conocimiento teórico. Por eso, el estudio del regionalismo tiende a centrarse en estudios de caso, lo que permite capturar su singularidad pero genera problemas de comparabilidad.

Lo han estudio bien los colegas del Instituto sobre estudios comparados de integración regional de la Universidad de Naciones Unidas en Brujas. En un trabajo fundamental para esta disciplina, Regionalism, la compilación en 4 volúmenes de las principales aportaciones al tema, Fredrik Soderbaum y Philippe de Lombaerde ilustran la idea acudiendo a Sbaragia: "El estudio del regionalismo comparado está enfermizamente definido" o del propio Soderbaum cuando dice "No hay prácticamente debate sistemático sobre los fundamentos de la comparación".

Pero el segundo problema metodológico que quería mencionar está también relacionado con el ejercicio de comparar y es el eurocentrismo. He sido Chair los dos pasados años 2017 y 2018 de la Sección Europa-América Latina de LASA (Latin American Studies Association) y en los últimos congresos de esta asociación ha habido un clamor contra el uso de la UE como referencia de la integración y contra los problemas que ha generado este sesgo en el análisis latinoamericano.

Soderbaum y De Lombaerde han explicado el problema como el The $N=1$ problem.

El sesgo eurocéntrico tiene que ver, por una parte, con la historia del regionalismo contada por olas: 
- La clásica - Classical Regional Integration (1945-1970)

- La revision de la clásica-Revisions of Classical Regional Integration (1970-1990)

- O The New Regionalism (1990-2000)

Se trata de un esquema temporal que hace que los inicios del análisis nazcan del caso europeo.

Y por otra, tiene que ver con la presunta y errada percepción de que no con que comparar. Cuando como dicen los autores $\mathrm{N}$ es $>1$ y hay abundancia de casos en todo el mundo: Asia, África, América, Norte de África y Medio Oriente.

Otros autores han definido el problema. Breslin y Higgot decían

La suposición de que la UE es el ejemplo de la integración es uno de los principales obstáculos para el desarrollo de estudios comparativos analíticos y teóricos de la integración regional.

Hurrel decía

El estudio del regionalismo comparado se ha visto obstaculizado por las llamadas teorías del regionalismo, que resultaron ser poco más que la traducción de un conjunto particular de experiencias europeas a un lenguaje teórico más abstracto.

Hicimos hace años con José Juan Romero un trabajo de gran divulgación sobre las claves para entender la UE que nos anima a matizar esa afirmación, pero es fácil entender la crítica sobre una comparación que ha llevado a mimetismos inconvenientes particularmente en el desarrollo institucional. El equipo de profesores que en esta Universidad trabajamos sobre el tema (Vicente González, Francis Santos y yo mismo) tratamos de deslindar lo que sí es referencia útil de la experiencia europea y no genera sesgos en el análisis. Los modos de ejecución de las políticas regionales son un caso claro y esperamos nos lleven a conclusiones interesantes para el regionalismo latinoamericano.

Decía antes que la del regionalismo latinoamericano es otra de las dimensiones en esta crisis de la integración regional. Las olas del regionalismo en América Latina han generado varias iniciativas muy conocidas. Además de la vieja ALADI, surgieron desde los años 60 el llamado MCCA (luego SICA), la CAN, el Caricom en los 70 y el MERCOSUR ya en los noventa. Procesos de integración tradicional porque buscaban implementar, compartiendo soberanía, uniones aduaneras con algunas políticas sectoriales de apoyo que han ido ampliando su rango. Un parecido sospechoso con el proyecto europeo. En los años noventa surgieron varias propuestas de regionalismo pero que se limitaban al libre comercio (el ALCA, el 
TLCAN). De entonces en adelante se produjo la misma proliferación de TLC que a escala global.

Pero en el año 2005 durante la Cumbre de las Américas celebrada en el Río de la Plata, los países latinoamericanos (la Argentina de Kirchner, el Brasil de Lula, la Venezuela de Chávez y otros) dieron un portazo definitivo al ALCA. Ese momento dio paso a la particular ola del llamado regionalismo postliberal que se desarrolló a partir de la creación del ALBA y la UNASUR y que dio lugar también a la CELAC que es la entidad interlocutora de la UE en las relaciones birregionales. Las novedades conceptuales y políticas que proponía este regionalismo postliberal generaron una sensación de auge en la integración que ha durado varios años y que fue fervientemente analizado por parte de la academia. Sin embargo, la Alianza del Pacífico es hoy la única propuesta contemplada con interés, por su vocación revocatoria del regionalismo postliberal, en un marco de crítica generalizada a la viabilidad de la integración en LAC.

Las críticas se centran en varias afirmaciones tajantes sobre la falta de voluntad de los países latinoamericanos, la ineficacia de la institucionalidad y del marco legal de los procesos, o la incapacidad de las iniciativas para generar efectos o avances tangibles en beneficio de los ciudadanos.

La alternancia de las fases de alabanza y crítica forman parte de un comportamiento que se cíclicamente desde los años 60 . Existe un patrón en este comportamiento que implica una fase inicial de entusiasmo político y normativo que tiende a durar en torno a 10 años (o dos legislaturas). Tras estos años viene la crisis y el proceso es acusado de retórica, ineficacia y sesgos ideológicos. Otra iniciativa de naturaleza diferente o contraria absorbe la atención y el protagonismo político. Tras esta fase, el proceso entra en una cierta inercia y olvido pero difícilmente se cierra, engrosando la procesión de muertos vivientes de la integración latinoamericana que tan mala reputación genera.

En colaboración con colegas latinoamericanos, estoy trabajando en la categorización de estos patrones para explicar esos "cambios de humor" y o bien preverlos, o bien evitarlos. Hay variables evidentes como el presidencialismo, la falta de interés explicito común de los miembros de la iniciativa o la insuficiente o reducida interdependencia en términos económicos o de desarrollo. La investigación nos debe ayudar a responder a preguntas como la de si la Alianza del Pacífico, hoy aclamada por sus innovaciones, repetirá o no ese patrón y languidecerá en no menos de 5 años. $O$ puede ayudar a dilucidar si tiene sentido mantener los proyectos del Mercosur, la Comunidad Andina o la UNASUR o es mejor clausurarlos para no condicionar futuras propuestas. 
En un trabajo que estamos finalizando otro grupo de colegas del Departamento de Economía ( $M^{a}$ Carmen López, Ana Hernández, Jesús Lasarte y yo mismo) hemos analizado varios índices de interdependencia económica sugeridos por el UNU-CRIS para medir el fundamento de algunos de los procesos o para dar pistas sobre cuál podría ser su vocación.

Los resultados confirman algo que llevamos señalando hace tiempo y es que el SICA, la integración centroamericana, es el proceso más relevante en la integración latinoamericana por muy pequeño que sea el protagonismo global de sus países. Por diversas razones, pero una destacada es la interdependencia de sus economías.

El debate sobre la integración como herramienta del desarrollo puede apoyarse en estas cifras de interdependencia económica para corroborar la falta de transformaciones asociadas a la CAN o el MERCOSUR o el poco fruto de la Alianza del Pacífico. No obstante, una lectura más estratégica nos lleva a destacar la dependencia de los países sudamericanos de los mercados externos y las pobres cifras de su comercio intrarregional. ¿ No debería ser un punto destacado de la agenda la diversificación de mercados apostando por el de los vecinos en vez de centrar todas las apuestas en China, USA o el lejano Oriente?

La dependencia entre desarrollo y regionalismo o integración es para nosotros evidente en el caso de los pequeños, vulnerables y empobrecidos países centroamericanos. Nuestro trabajo académico en torno a ese proceso ha dado lugar ya a varias tesis doctorales y en el marco de Doctorado en desarrollo inclusivo y sostenible hay varios doctorandos trabajando sobre ello. Analizando cómo descomponer el inexacto argumento de la falta de voluntad política, estudiando los condicionantes de la eficacia de las políticas públicas regionales, definiendo la naturaleza de los intereses nacionales que sustentan la integración y el impacto de la cooperación internacional en apoyo al SICA.

En un entorno como el centroamericano, el desarrollo de sus países necesita de la dimensión complementaria de la acción conjunta regional:

- Para compensar las dinámicas excluyentes que marcan sus sociedades.

- Para optimizar los procesos de desarrollo y los escasos recursos con los que cuentan países pequeños y vulnerables como los centroamericanos.

- $O$, entre otras opciones, para corregir los riesgos del círculo vicioso entre la exclusión, la violencia y la falta de democracia. 
Los avances del proceso de Paz de Esquipulas durante los años noventa no han sido suficientes para romper esas dinámicas. Hoy asistimos con preocupación a la crisis nicaragüense y a la represión gubernamental que afecta a tantos amigos nuestros y a todo un país al que esta universidad está unida por múltiples lazos y que aprovecho para hacer presente así en nuestra sesión inaugural del curso.

No es sólo Nicaragua la que está en conflicto. El circulo vicioso entre exclusión, violencia y autoritarismo o corrupción vuelve a coger fuerza en la región. El enfoque regional del desarrollo y el SICA como instrumento es pieza fundamental en el puzzle centroamericano.

Quiero terminar la lección inaugural hablando de la dimensión europea de la crisis, que les resultará probablemente más cercana a nuestro día a día que lo que he contado hasta ahora.

No es la primera vez que la UE está en crisis. Pero esta vez es diferente. Quién expresó mejor la sensación de estupefacción fue el Papa Francisco en su discurso de agradecimiento al recibir el Premio Carlomagno en el 2016. Cuando se preguntaba "¿Qué te ha sucedido, Europa humanista, defensora de los derechos humanos, de la democracia y de la libertad? ¿Qué te ha pasado, Europa?"

La UE ha mostrado siempre una notable capacidad para resolver sus crisis con soluciones creativas que forman ya parte del relato de la integración europea. Lo han ilustrado metáforas como la del reloj parado, la silla vacía, la bicicleta lenta pero que no deja de pedalear, o la procesión de Etternach en Luxemburgo, esa que avanza, aunque lo hace al ritmo de 3 pasos adelante y dos pasos atrás. Frente a la amenaza del desacuerdo o la ruptura, contábamos con la certeza de que al final esperaba siempre la voluntad de consenso.

Sin embargo, esta crisis no parece reproducir el patrón de otras en la historia de la Unión Europea. No hay que resistirse a calificar la crisis como la primera en la que se puede haber producido una ruptura de los principios que han definido la Unión Europea. La relevancia del proyecto político y social que hay detrás de la UE y su larga lista de logros es tan valiosa que genera vértigo cuestionarla.

Usando de nuevo el símil de la bicicleta, la receta es siempre apretar con fe los pedales para retomar velocidad tras las crisis. Pero ìy si el problema no fuera la intensidad en el pedaleo sino la necesidad de cambiar la bicicleta o de arreglarla? 
La crisis de la UE se ha manifestado en varios frentes. Tres asuntos han atormentado especialmente en estos años a la Unión Europea.

La dimensión más espectacular de la crisis ha sido el Brexit. Su importancia va más allá de la salida de uno de los cuatro grandes socios de la UE y de los efectos que provocará. Es la primera vez que un país quiere abandonar el proyecto desde su constitución.

Pese a la alarma inicial y a las novedades posteriores a este discurso, es evidente que el impacto del Brexit es una incógnita 5 . Nos parecía obvio que el Brexit debilitaría a la UE como bloque y no debemos descartarlo. Pero, sacando del grupo a un socio siempre disconforme, se ha producido una imprevista mejora de la autoestima y un cierto desatasco de algunos debates.

La crisis de los refugiados ha sido el episodio más triste de la crisis de la UE. El caso de los refugiados es especialmente grave para la Unión Europea más allá de sus complicaciones inmediatas en términos económicos, políticos y logísticos.

La amenaza del terrorismo en Europa introduce una dificultad excepcional ante la necesidad de dar respuesta a los refugiados y a la inmigración porque contribuye a fomentar el interés por limitar la libre circulación de personas y la entrada de refugiados. El miedo es razonable pero muy mal consejero.

La reacción de la UE y sus estados miembros ha sido decepcionante. La UE cumple mal los acuerdos internacionales sobre protección de los refugiados y desatiende el deber de socorro a los afectados por conflictos a los que la UE no es ajena. Los Estados Miembros incumplen los acuerdos sobre reparto de los refugiados propuestos desde la Comisión Europea y con el impulso de Alemania y otros países.

Esos gestos denotan la falta de capacidad del marco institucional comunitario para imponer las decisiones acordadas y transmite una mala percepción sobre su funcionamiento. Dan aire además a liderazgos de corte nacionalista y excluyente que responden muy mal a lo que se ha considerado como principios del modelo europeo. La incapacidad de reaccionar ante el problema es devastadora para

\footnotetext{
${ }^{5} \mathrm{El}$ texto original del discurso valoraba la posibilidad de un segundo referéndum que facilitase una suspensión definitiva del Brexit. El resultado de las elecciones generales de 2019 en el Reino Unido parece descartar definitivamente esta opción después de un período lleno de sorpresas y poco edificante en lo que era percibido como un sistema político equilibrado.
} 
la idea de la UE como potencia global, más aún como la potencia benigna que aspiramos a ser.

\section{El más importante: el fracaso de las políticas de austeridad y la crisis del euro}

El episodio más importante de la crisis de la UE es seguramente la crisis de la UEM y las políticas de austeridad con las que Europa ha reaccionado a la crisis global.

Como EEUU y el G20, también la UE paso del entender la crisis como un efecto de los procesos de desregulación del sistema financiero en todo el mundo y en los fallos de los mecanismos de supervisión públicos y privados (auditoras, agencias de evaluación y rating). A entenderla como la crisis de deuda pública que se impuso posteriormente.

Las políticas de reacción a la crisis han generado efectos económicos con implicaciones políticas importantes: un desempleo notable, el deterioro de las condiciones salariales y de la estabilidad de los contratos, economías poco capaces de crecer, pocos cambios en la estructura productiva que den aliento a un futuro diferente $y$ una desigualdad inédita en las últimas décadas. Todos son factores que amenazan la idea del estado social europeo. Observamos además con preocupación que los vientos de cola que impulsaban la recuperación estos años se han frenado. Suben los precios del petróleo, se frenan las políticas monetarias súper-expansivas del BCE y el turismo modera sus cifras.

Paul De Grauwe es uno de los economistas europeos con más relevancia en el análisis de la crisis del euro. Su balance se ha centrado en tres aspectos. En primer lugar, en el análisis de las debilidades de la gobernanza del euro y su diseño inicial y de la eficacia de las medidas de coordinación de políticas que se han adoptado para enfrentarlas y para profundizar la Unión económica y Monetaria.

En segundo lugar, en el fracaso de las políticas de austeridad. De Grauwe ha insistido en la necesidad de combinar la austeridad en los países periféricos más afectados por la crisis con estímulos fiscales en los países no deficitarios del norte para así contrarrestar las fuerzas deflacionarias. Se trata de un debate no cerrado y en el que los partidarios de los estímulos fiscales para moderar la soledad de la política monetaria. 
En tercer lugar, reclama a la UE y al Eurogrupo haberse dejado influir excesivamente por las percepciones sesgadas de los mercados financieros en sus decisiones sobre las políticas de austeridad, aceptando el diagnóstico erróneo de la crisis como un problema más de oferta e insistiendo inútilmente en una austeridad excesiva.

El euro es mucho más que un acuerdo sobre política monetaria y cambiaria. Es un símbolo de la integración europea y su carta de presentación como potencia global ante el mundo. Es una buena idea que no se diseñó bien. El proyecto debe ser corregido.

Las últimas señales ofrecen una respuesta positiva desde la siempre criticada tecnocracia europea y de sus instituciones. La UEM, el euro, tienen en su agenda varios asuntos críticos junto a la tardía pero persistente (y discutida) política monetaria expansiva del BCE. Uno de ellos es la creación de instrumentos financieros para compensar la crisis (el MEDE, mecanismo europeo de estabilidad, un futuro FMI europeo como sueñan algunos). El segundo asunto es el camino a la unión bancaria, que ya está avanzado en términos de supervisión y resolución bancaria pero que encuentra dificultades importantes para crear un fondo europeo de garantía de depósitos. La presión de la crisis ha incorporado un tercer asunto al debate, el de la política fiscal, cuyo avance pierde fuerza pero que ha introducido debates interesantes en materia de la armonización de las políticas tributarias y de los niveles de presión fiscal. Son también muy interesantes las posibilidades para evitar las prácticas que facilitan la elusión fiscal.

\section{¿Cuándo fue que se malogró el proyecto europeo?}

Se menciona con frecuencia en la literatura académica que fue al aprobar Maastricht y crear el proyecto del euro a principios de los noventa. Aunque es una fecha que puede servir como fecha de lanzamiento del rechazo ciudadano a la UE que no han dejado de crecer desde entonces, el Tratado de Maastricht en sí mismo no parece amenazar las esencias del modelo europeo de integración.

Hay una fecha que es mejor candidata para definir esto que llamo el riesgo de ruptura del modelo europeo y ésta podría ser el año 2004 que confirmó la ampliación de la UE a 10 nuevos socios, a los que poco después se unen dos más en el año 2007 y Croacia después. No porque entraran países con intereses y tradiciones culturales diferentes, de los que surgen hoy algunos gobiernos de corte nacionalista. Sino porque ganaron la partida los defensores de una europea más amplia y menos profunda, menos comunitaria y más economicista. 
El debate estuvo bien representado aquellos años por el contraste de dos discursos que tuvieron mucho impacto. Por una parte, el discurso de Tony Blair en octubre del año 2000 en Varsovia ${ }^{6}$, A superpower, but not a superstate. Un discurso que representaba una apuesta por una Europa más amplia pero no más profunda y que planteaba límites a la supranacionalidad de la UE de manera abierta y sugería de forma implícita pero poco visible entonces, la reducción de los mecanismos de solidaridad intraeuropea sobre los fundamentos de modelo social y económico de tipo anglosajón.

Por otra parte, el discurso inspirado en la versión más ambiciosa de la propuesta supranacional, presentado por el entonces canciller alemán, el verde Joschka Fischer en Berlín el 12 de mayo del 2000 bajo el título From Confederacy to Federation. Thoughts on the finality of European integration ${ }^{7}$.

Pese a la ampliación de 15 a 28 miembros, las previsiones financieras de 2000-2006, las de 2007-2013 y las de 2014-2020 reforzaron consecutivamente la contención presupuestaria y con ello la limitación de la profundidad de las políiticas europeas.

Lo decía muy expresivamente el editorial de la Revista de Fomento Social (Consejo editorial 2006:162):

En el fondo, ambas crisis, la de la Constitución y la de las perspectivas financieras, son como las dos caras de la misma moneda: la de una aparente crisis de crecimiento del modelo europeo. Con audacia, y con una fuerte dosis de generosidad, la ampliación de 2005, de 15 a 25 países, supuso un salto cualitativo, no sólo cuantitativo. Pero el frenazo sufrido a la hora de poner los medios para que el modelo tenga futuro pone en cuestión el proceso mismo.

\section{¿Qué hacer con la UE?}

La UE celebró el pasado 25 de marzo de 2017 el 60 aniversario del Tratado de Roma entre estos malos presagios. Con timidez sobre si celebrar los logros de la UE. Pero pocas cosas hay mejores que la integración en la historia de los últimos

${ }^{6}$ Discurso del primer ministro británico Tony Blair en el Mercado de valores de Polonia en Varsovia el 6 de octubre de 2000: "A superpower, but not a superstate".

7 Discurso del Ministro de Asuntos Exteriores alemán, Joschka Fischer en la sde de la Humboldt University en Berlín el 12 de mayo del 2000 bajo el título "From Confederacy to Federation. Thoughts on the finality of European integration". 
siglos de Europa. La idea de ver unida a gente tan diversa en torno a objetivos comunes es un fantástico logro de la UE.

En marzo de 2017, Jean Claude Juncker se preguntaba ¿Quo vadis Europa? usando las palabras del Papa Francisco para presentar el Libro Blanco sobre el Futuro de Europa (Comisión Europea, 2017).

Un texto de fundamentos inusualmente débiles para lo habitual en el marco de la CE. Como señalaron muchos autores en sus primeras reacciones al texto, se trataba de una respuesta insuficiente, un documento centrado en la estrategia y no en el contenido o los principios del modelo. Sin embargo, puede que se trate de un instrumento pedagógico útil para el debate ante la ciudadanía europea.

El texto ofrecía cinco escenarios de futuro: seguir igual, intentando cumplir su programa de reformas positivas; centrarse gradual e únicamente en el mercado único; permitir que los que desean hacer más, hagan más, el escenario de la Europa a varias velocidades; hacer menos pero de forma más eficiente, un escenario de simplificación de la UE escondido tras la eficiencias; y el voluntarioso quinto escenario de la profundización de la integración, hacer mucho más conjuntamente en todos los ámbitos.

El escenario de la Europa de las múltiples velocidades, los que quieran hacer más, que hagan más, ya ensayado en Schengen o en el euro, parecía el escenario de futuro más probable, el apuntado por las principales potencias de la UE o por ejemplo, por The Economist. Hoy, sólo año y medio después parece descartado.

Cabe preguntarse si es una buena señal o es que los atenuantes de la crisis no empujan a evitar decisiones importantes.

La salida de la crisis se debería centrar entonces en evitar la tentación de la ruptura del modelo. La agenda de futuro debe evitar la opción de dar marcha atrás, pero tiene que reinventarse a partir de la respuesta a las necesidades de la Europa del siglo XXI. Recuperar las raíces de la UE, encontrando un proyecto común, desarrollado en conjunto a partir del juego de suma positiva de sus intereses combinados, permitiendo que los estados miembros de la UE amparen a sus ciudadanos tras la crisis y ofreciéndoles una sociedad con instrumentos para competir y garantizar una prosperidad inclusiva. $Y$ aspirando también a extender su impacto positivo a una sociedad global que también genere oportunidades para todos, sin dejar a nadie atrás. 
¿Qué significaría eso en los términos actuales del debate? Las políticas de la UE merecen una profunda revisión, que rompa inercias, pero que no sea excusa para la contención presupuestaria. No hay proyecto ambicioso que no esté asociado a mayor presupuesto. Tampoco a un sistema de decisiones que evite los vetos y bloqueos, aunque para ello deba imponer un Europa de varias velocidades.

El futuro nos permite ser optimistas tras muchos años de perspectivas oscuras. Al libro blanco sobre el futuro de Europa le han seguido otras propuestas que parecen confirmar un nuevo escenario. El discurso de Emmanuele Macron en La Sorbona el 26 de septiembre de 2017, las propuestas de Juncker en el discurso del estado de la UE el 13 de septiembre de 2017 o las interesantes sugerencias de Donald Tusk (Building our future together) a los líderes europeos en el Consejo de la UE del 19 y 20 octubre de 2017 en Tallin (Estonia) marcan una agenda aparentemente más ambiciosa y mejor entroncada con el futuro. Las elecciones alemanas provocaron un parón en esa dinámica de propuestas y urge que los liderazgos recuperen el tono.

Dos hitos van a marcar a corto plazo la ambición del proyecto europeo y las ganas de recuperar su potencial. El primero es la negociación de las previsiones financieras 2021-2027 y las reformas presupuestarias asociadas a esta negociación.

El segundo es el movimiento político que seamos capaces de impulsar en torno a la celebración de las elecciones al Parlamento Europeo en mayo de 2019. ¿ Se imaginan que la falta de participación permita un Parlamento Europeo lleno de euroescépticos o nacionalistas, de radicalismo antieuropeo?

Me parece que la Universidad tiene que responder a este reto haciendo dos cosas. Ser activa y valiente en la batalla de las ideas para recuperar lo mejor de nuestro proyecto común de futuro y espantarlas ideas falsas y excluyentes. Y movilizar a los jóvenes para que tomen las riendas de su futuro con posiciones activas en esas elecciones y una votación lo más masiva posible.

Muchas gracias. 